\title{
Cumin Oil
}

National Cancer Institute

\section{Source}

National Cancer Institute. Cumin Oil. NCI Thesaurus. Code C107296.

The oil extracted from the seeds of Cuminum cyminum. Cumin oil is used in treatments of the digestive system. 